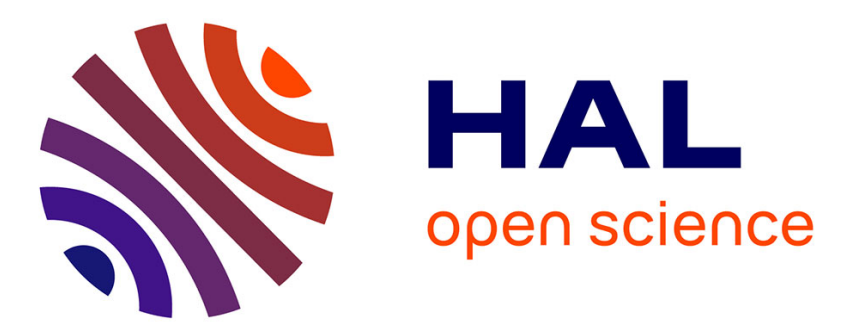

\title{
Current Controller for Low Frequency Signal Injection and Rotor Flux Position Tracking at Low Speeds
}

Duro Basic, François Malrait, Pierre Rouchon

\section{To cite this version:}

Duro Basic, François Malrait, Pierre Rouchon. Current Controller for Low Frequency Signal Injection and Rotor Flux Position Tracking at Low Speeds. IEEE Transactions on Industrial Electronics, 2011, 58 (9), pp.4010 - 4022. 10.1109/TIE.2010.2100336 . hal-00576882

HAL Id: hal-00576882

https:/ /hal-mines-paristech.archives-ouvertes.fr/hal-00576882

Submitted on 15 Mar 2011

HAL is a multi-disciplinary open access archive for the deposit and dissemination of scientific research documents, whether they are published or not. The documents may come from teaching and research institutions in France or abroad, or from public or private research centers.
L'archive ouverte pluridisciplinaire HAL, est destinée au dépôt et à la diffusion de documents scientifiques de niveau recherche, publiés ou non, émanant des établissements d'enseignement et de recherche français ou étrangers, des laboratoires publics ou privés. 


\title{
Current Controller for Low Frequency Signal Injection and Rotor Flux Position Tracking at Low Speeds
}

\author{
Duro Basic, Francois Malrait, Member, IEEE, Pierre Rouchon
}

\begin{abstract}
Rotor flux spatial position can be tracked in an ac machine even at low or zero stator frequency if a low frequency harmonic current signal is injected into its stator. The harmonic current injection is source of the rotor speed perturbations which induce voltage oscillations in the stator winding at the injected frequency. By analyzing the stator winding voltage response it is possible to detect the rotor flux position regardless of the stator frequency. This paper presents a stator current controller suitable for imposing rotating or pulsating harmonic current injection and a method for tracking the rotor flux position in either induction machines (IM) or permanent magnet synchronous machines (PMSM). The controller contains, in addition to the standard fundamental frequency based synchronous reference frame (SRF) current controller, two sets of harmonic current integral controllers placed in respective harmonic SRFs. Such extended current controller performs simultaneously two important tasks: controlled harmonic current injection with zero steady-state error and separation of particular spectral components in the stator voltage (spectral/sequence decomposition) which contain the rotor flux position information. The theoretical analysis presented, based on perturbation theory and averaging techniques, gives general expressions which link the rotor flux position error in IM and PMSM to the harmonic current controller outputs. Two special cases with the rotational and pulsating harmonic current injections are considered in more details. Validity of the theoretical analysis and feasibility of the sensorless rotor flux position detection are experimentally verified.
\end{abstract}

Index Terms - Senorless control, signal injection, induction machine drives, permanent magnet synchronous machine drives.

\section{NOMENCLATURE}

$\begin{array}{ll}\omega & \text { rotor electrical speed } \\ \tau_{r} & \text { rotor time constant IM } \\ \tau_{l} & \text { load torque } \\ \theta_{r}, \theta_{s} & \text { controller (stator) and rotor flux angle frame angles } \\ & \text { with respect to stationary frame }\end{array}$

Manuscript received April 30, 2010. Accepted for publication November 29, 2010.

Copyright (C) 2009 IEEE. Personal use of this material is permitted. However, permission to use this material for any other purposes must be obtained from the IEEE by sending a request to pubs-permissions@ieee.org.

D. Basic was with Schneider Electric, Pacy-sur-Eure, France. He is now with General Electric, Controls \& Power Electronics CoE, Garching b. Munich, Germany (phone: +49(0)89 55283-929; fax: +49(0)89 55283-929; e-mail: duro.basic@ge.com).

F. Malrait is with Schneider Electric, Pacy-sur-Eure, France (e-mail: francois.malrait@schneider-electric.com).

P. Rouchon is with the Mines ParisTech, Centre Automatique et Systèmes, Mathématiques et Systèmes, Paris 75272, France (e-mail: pierre.rouchon@mines-paristech.fr). $\theta_{h}$

$\varphi_{m}$

$\varphi_{s}, \varphi_{r}$

$\varepsilon$

$\delta x$

$\alpha, \beta$

$\Omega$

$\Delta L$

$n_{p}$

$x^{*}$

$\bar{x}$

$v_{s,} i_{s}$

$V^{0}$

$V^{+}, V$

$R_{s}$

$R_{\text {req }}$

$R_{e q}$

$o,+,-$

$L_{s}, L_{r}, L_{m}$

$L_{f}$

$L_{d}, L_{q}$

$L$

$K_{p \varepsilon}, K_{i \varepsilon}$

$K_{p}, K_{i}$

$K_{i h}$

$J$

$I^{+}, I^{-}, I$

$f_{s}, \omega_{s}$

$d, q$

$\dot{x}$

\author{
harmonic controller angle with respect to fundamental \\ frequency control frame \\ magnet flux in PMSM \\ stator and rotor flux \\ rotor flux position seen in control frame \\ perturbed component of variable $\mathrm{x}$ \\ indexes for variables in stationary frame \\ frequency of injected signal \\ saliency inductance in PMSM \\ number of pole pairs \\ conjugation of complex variable $\mathrm{x}$ \\ time-averaged component of variable $\mathrm{x}$ \\ motor complex voltage and current \\ fundamental frequency stator voltage \\ $+/$ - sequence harmonic voltage injection \\ stator winding resistance \\ equivalent rotor resistance in $\left(\mathrm{R}_{\mathrm{r}}\left(\mathrm{L}_{\mathrm{m}} / \mathrm{L}_{\mathrm{r}}\right)^{2}\right)$ \\ equivalent resistance in IM \\ indexes for variables in fundamental frame or $+/$ \\ sequence harmonic controller frames \\ stator, rotor and magnetising inductance in IM \\ equivalent total leakage inductance of IM \\ $\mathrm{d}, \mathrm{q}$ axes stator inductances in PMSM \\ average stator inductance in PMSM \\ proportional and integral gain of position rotor tracking \\ loop \\ proportional and integral gain of fundamental \\ frequency current controller \\ gain of harmonic integral controller \\ mechanical inertia \\ $+/$ - sequence harmonic current injection \\ stator frequency \\ indexes denote variables in controller frames \\ time derivative $\mathrm{dx} / \mathrm{dt}$
}

\section{INTRODUCTION}

Sensorless vector control of ac machines (with no rotor position feedback) at zero and very low stator frequencies presents a major challenge because the rotor flux position can not be observed in the fundamental frequency stator current and voltage signals. In an effort to overcome this limitation of the fundamental frequency based sensorless control methods injection of various test signals (at frequency different than the fundamental) have been proposed for the rotor or rotor flux position detection [1-13]. Typically, in literature as well as in this paper, such signal injections are classified as 'harmonic' injections although (in general case) their frequencies do not have some specific relation with the fundamental frequency. In principle we can distinguish two major groups of the harmonic injection methods: one is based on high [1-4] and other is based on low frequency harmonic signal injection [513]. 
The high frequency signal injection based methods [1-4] are used to detect spatial variations of the machine leakage (IM) or synchronous (PMSM) inductances to estimate the rotor flux position. The inductance variations can be caused by magnetic saturation or rotor geometric saliency and thus these methods may not be compatible with all rotor designs. The injected signal is usually in the $0.5 \mathrm{kHz}-2 \mathrm{kHz}$ range. Typically harmonic voltage injection is generated by the drive inverter as it is difficult to provide precise closed loop current control if the injection frequency is high (current controller bandwidth limitations). A rotational [1,2] or pulsating (alternating) $[3,4]$ harmonic vector voltage reference is added to the inverter voltage references in the fundamental frequency current controller reference frame. The flux position error is extracted by demodulation/heterodyning processing of a specific component in the current response at the injection frequency. If the rotational injection is performed, the position error signal is embedded in the negative sequence current vector at the injected frequency [1]. With the pulsating signal injection, typically applied in the controller $d$ axis, the position error signal is embedded in the $q$ axis current component at the injection frequency [2]. The high frequency injection signal tends to create relatively strong audible noise which may not be acceptable in some applications. To avoid explicit high frequency signal injection there are attempts to estimate the position error by detection of the current ripple caused by the inverter pulse width modulation $[14,15]$.

The so called low frequency harmonic current injection method [5-13] is based on excitation of small torque and rotor speed oscillations capable of inducing oscillations in the stator back electromotive force (emf.) which can be detected in the stator voltage response at the injection frequency (typically in $25 \mathrm{~Hz}-100 \mathrm{~Hz}$ range). Information on the rotor flux spatial position can be retrieved from the phase of this voltage spectral component (voltage phase observed relative to the injected current phase). Thus for good position accuracy precise (stiff) control of the current injection is important. Application of this principle has been reported for initial rotor flux position detection in PMSM [5] and sensorless vector control of IMs [7-10] and PMSMs [11-13]. Normally a pulsating harmonic current vector is injected into the $d$ (flux) axis of the fundamental frequency controller reference frame as then the injection results in minimal torque oscillations [713]. When the measured stator voltages are not available (often the case in standard variable speed drives) the voltage references at the stator current controller outputs are used for detection of the machine voltage response. However in this case effects of the inverter switches dead time and voltage drop should be considered as they appear as sources of distortion (error) in the injected voltage which is periodically modulated by multiple zero-crossings of the phase currents imposed by the injected current [4].

Basic problems in application of the low frequency harmonic injection based method are to achieve precise harmonic current vector injection and retrieve the voltage component from the current controller outputs conveying the rotor flux position error information. The approach reported in recent work [7-13] is to perform the harmonic current injection using the standard (fundamental) current synchronous reference frame proportional integral (PI) controllers. One disadvantage of such approach is that it cannot ensure precise harmonic current injection with zero steady state error even if the controller is set with high bandwidths. In addition, to isolate the stator voltage components carrying the rotor flux position information in the manner used in [7-10], considerable signal processing effort, use of the stator voltage equations and knowledge of several machine parameters are required (resulting in sensitivity to parametric errors [10]).

The harmonic current injection and rotor flux position estimation method proposed in this paper has several advantages over the method reported in [7-13]. It can provide simultaneously precise harmonic current injection and perform isolation of the spectral component in the stator voltage response relevant for the rotor flux position error retrieval without using the machine model. It is based on the standard stator current SRF PI controller is expanded by two sets of SRF based harmonic integral (I) controllers. Such current controllers are frequently used in active power filter control systems for selective and precise compensation of several targeted harmonics [16,17] or in PWM rectifier control [18]. In our case one set of the harmonic I controllers is placed in a SRF rotating at the harmonic frequency $\Omega$ (with respect to the fundamental frequency SRF) while the other set of the harmonic I controllers is placed in a SRF rotating at $-\Omega$ (in further text positive and negative sequence harmonic SRF controllers). With the harmonic I controllers centred at $\pm \Omega$ the current controller is capable of enforcing the stator current injection at both harmonic sequences and with zero steadystate tracking error. Simultaneously (due to infinite gains of the SRF based integrators), the current integrator outputs (including the standard fundamental frequency integral controllers) directly separate the stator reference voltage into dominant spectral components without using any additional signal processing and with no knowledge of the machine parameters. Then the rotor flux position information can be directly retrieved from the harmonic current controller outputs.

The paper is organized as follows. Initially in Section III the current controller structure is presented. Further, assuming precise harmonic current injection, relations between the harmonic integral controller outputs and rotor flux position error are derived in systematic manner by using the averaging techniques and perturbation theory [19]. Two cases with IM (Section IV) and PMSM machine (Section V) are analyzed. In the both cases two characteristic types of harmonic current injections, rotating and pulsating, are considered in more details. Based on the derived expressions Section VI presents a simple rotor flux position tracking system and sensorless flux oriented control based on direct extraction of the rotor flux position error from the harmonic current controller outputs. Finally in Section VII some experimental results are presented to validate the theoretical analysis. These experimental results confirm that the rotor flux position error 
information can be effectively extracted by using the proposed method with either rotational or pulsating harmonic injection. It is also experimentally demonstrated that this error signal can be exploited for the rotor flux position tracking in the IM and initial rotor position detection in PMSM.

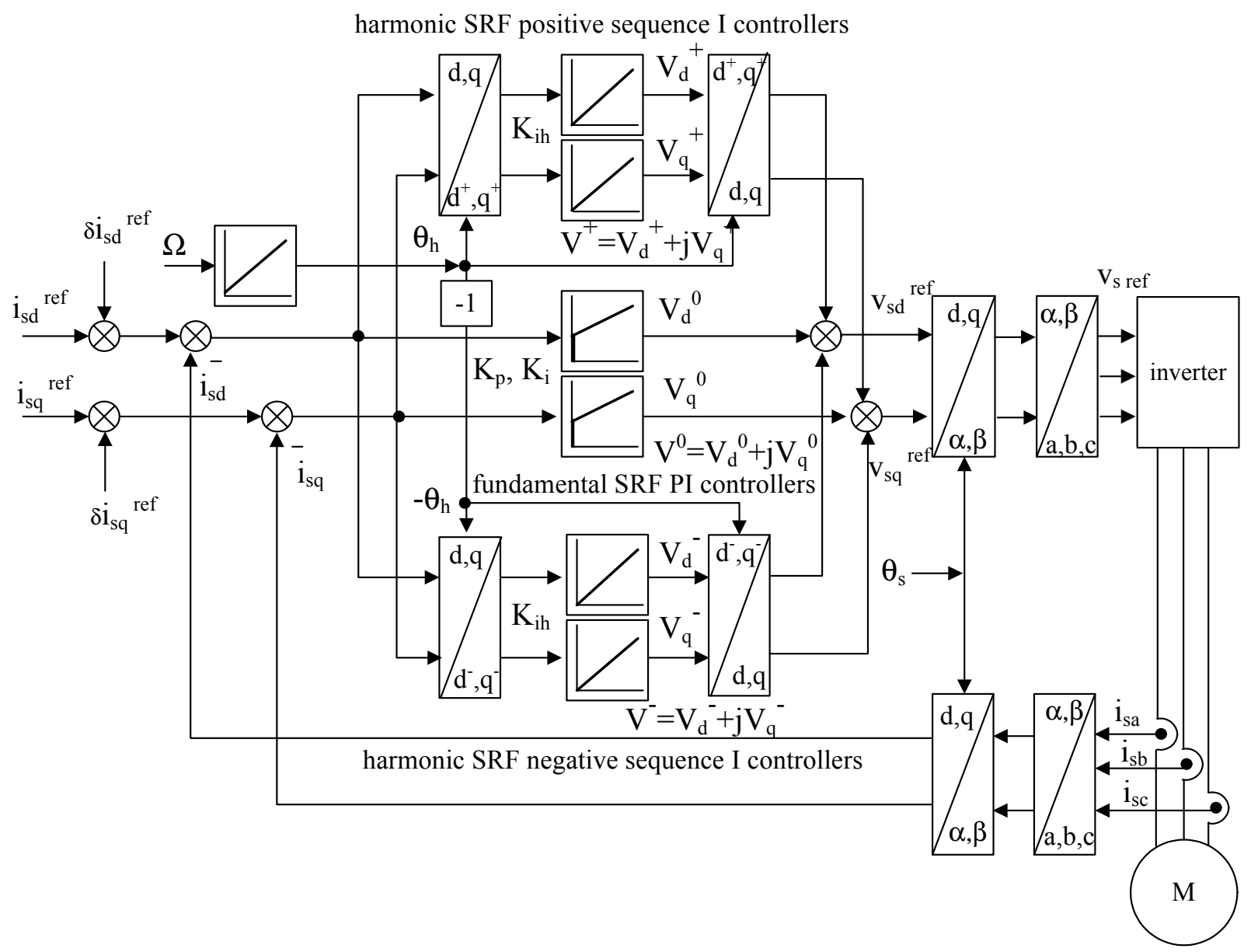

Fig. 1. Synchronous reference frame fundamental frequency current control scheme augmented by dedicated synchronous reference frame integral controllers for harmonic current control.

\section{CURRENT CONTROL SCHEME}

Block diagram of the current control scheme is shown in Fig. 1. It contains the standard SRF fundamental frequency current PI controllers with gains $K_{p}$ and $K_{i}$. Additionally two sets of harmonic current I controllers with gain $K_{i h}$ are added, placed in respective SRFs rotating at the harmonic injection frequency $\Omega$ in both directions. The fundamental current vector reference is set by external means such as torque/speed controller, flux controller etc. The harmonic current references are set independently at a level required for reliable flux position detection. Thanks to the harmonic I controllers, the current controller is capable of injecting rotating harmonic current vectors in either positive $(+)$ and negative $(-)$ sequence with zero steady state tracking error. Simultaneously the stator voltage references are decomposed into fundamental and harmonic spectral components (SRF integrator output vectors $V^{o+-}$ ) and $K_{i h}$ are strictly positive and $\Omega \neq 0$, see the Appendix 1 .
For further analysis the fundamental and harmonic current controller reference frames are defined as illustrated in Fig. 2.

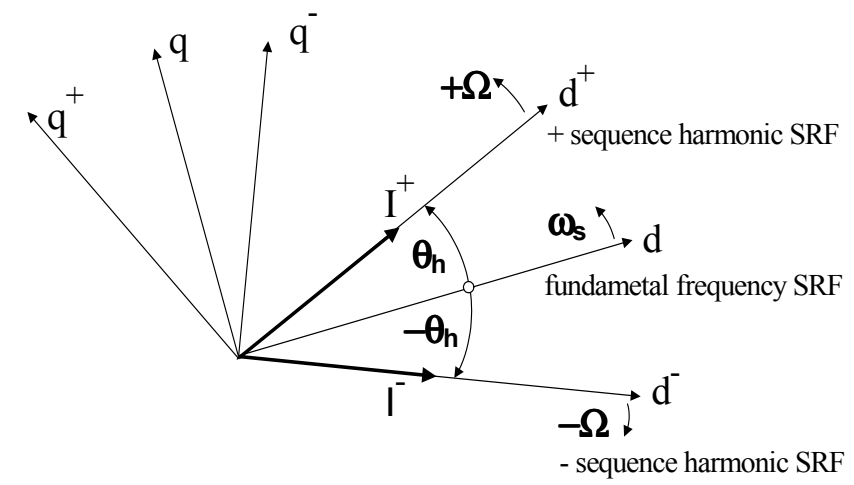

Fig. 2. Fundamental and harmonic frequency stator current controller reference frames. 
The rotor flux position angle $\varepsilon$ (tracking error) seen in the fundamental controller reference frame is defined in Fig. 3.

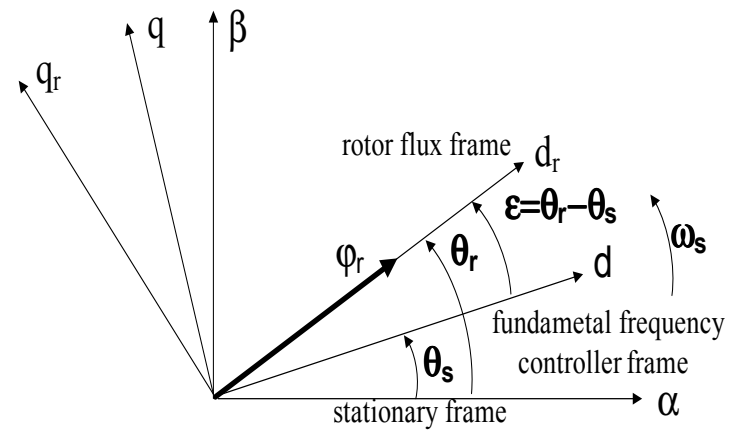

Fig. 3. Mutual position of the rotor flux and fundamental frequency current controller reference frames.

\section{Rotor FLUX POSITION ERROR SIGNAL IN INDUCTION MACHINES}

In this section the link between the rotor flux position error and outputs of the harmonic integral controllers are derived in case of an IM. We will start from the standard IM model which uses the stator current $i_{s}$, rotor flux $\varphi_{r}$ and rotor speed $\omega$ as the state variables. The stator current and rotor flux variables are complex ('*' means conjugation), bar above variables denote steady state/average variables while small signal perturbations around the steady state point are designated by a prefix $\delta$.

$$
\begin{aligned}
& v_{s}=L_{f} \frac{d i_{s}}{d t}-\left(\tau_{r}{ }^{-1}-j \omega\right) \varphi_{r}+\left(R_{e q}+j \omega_{s} L_{f}\right) i_{s} \\
& \frac{d}{d t} \varphi_{r}=-\left(\tau_{r}{ }^{-1}+j \omega_{s}-j \omega\right) \varphi_{r}+R_{r e q} i_{s} \\
& \frac{d \omega}{d t}=\frac{n_{p}}{J}\left(\tau_{e}-\tau_{l}\right) \\
& \tau_{e}=\frac{3 n_{p}}{2} \operatorname{Im}\left(\varphi_{r}{ }^{*} i_{s}\right)
\end{aligned}
$$

where $\tau_{r}$ is the rotor time constant, $\omega_{S}$ is stator frequency, $L_{f}$ is equivalent leakage inductance, $R_{e q}$ and $R_{r e q}$ are equivalent total and equivalent rotor resistance respectively, $n_{p}$ is number of pole pairs, $J$ is equivalent rotor inertia, $\tau_{e}$ and $\tau_{l}$ are electromagnetic and load torque respectively.

In addition to the fundamental current component it is assumed that a small harmonic perturbation current $\delta i_{s}$ of zero time average is injected into the stator by using the controller of Fig. 1:

$$
i_{s}=\bar{i}_{s}+\delta_{i_{S}}
$$

The perturbation current vector can describe in general case an elliptic trajectory which can be decomposed into the positive $\left(I^{+}\right)$and negative $(I)$ sequence rotating vectors:

$$
\delta_{i_{S}}=I^{+} e^{j \Omega t}+I^{-} e^{-j \Omega t}
$$

For approximate calculation of the perturbation components the perturbation technique and averaging method [19] are used. The system response will contain an average component and periodic perturbation. The average response is assumed to evolve in a slow time scale driven by the average term in the system equations. According to [19] the fast periodic response can be calculated by simple integration of the periodic components in the system equations assuming that the system response is slow (i.e. its bandwidth 5-10 times lower than the injection signal frequency $\Omega$ ). It is equivalent to approximating the system low pass filtering behaviour by pure integration of the periodic terms. In our case, considering the stator current perturbations at frequency $\Omega$, the dominant (first order) speed and rotor flux perturbations obtained after integration of respective state equations, will contain terms proportional to $1 / \Omega$. Effect of these first order speed and flux perturbations can be further considered in order to obtain more accurate approximation of the machine response. It is clear that after integration of the state equations (2) and (3) the first order perturbation terms in the sate variables will produce addition perturbations which will contain terms proportional $1 / \Omega^{2}$ (second order terms). One can further take into account effects of these second order terms and so on, and obtain an approximate asymptotic expansion of the solution (1-5) with respect to term $1 / \Omega$. When $\Omega$. is high enough, normally only several lowest order terms are sufficient for good approximation of the machine dynamic response as the higher order terms are rapidly diminishing.

In the IM case with the stator current injection defined by (6), the rotor speed dynamics is deduced from (3) and (4):

$$
\dot{\omega}=\frac{3 n_{p}^{2}}{2 J} \operatorname{Im}\left[\varphi_{r}^{*}\left(\bar{I}_{s}+I^{+} e^{j \Omega t}+I^{-} e^{-j \Omega t}\right)\right]-\frac{n_{p}}{J} \tau_{l}
$$

From (7), assuming that $\Omega$ is large enough, the speed perturbations dynamics $\delta \dot{\omega}$ can be separated from the average speeds dynamics $\dot{\bar{\omega}}$ by identifying periodic terms with zero time average:

$$
\delta \dot{\omega}=\frac{3 n_{p}^{2}}{2 J} \operatorname{Im}\left[\bar{\varphi}_{r}^{*}\left(I^{+} e^{j \Omega t}+I^{-} e^{-j \Omega t}\right)\right]
$$

After integration of (8) we obtain:

$$
\delta \omega=-\frac{3 n_{p}{ }^{2}}{4 J \Omega}\left(\begin{array}{c}
\left(\bar{\varphi}_{r}^{*} I^{+}-\bar{\varphi}_{r} I^{-}\right) e^{j \Omega t}+ \\
+\left(\bar{\varphi}_{r} I^{+}-\bar{\varphi}_{r}^{*} I^{-}\right) e^{-j \Omega t}
\end{array}\right)
$$

It should be noticed that the rotor flux perturbations are neglected in (7). The fact that ripple of the rotor flux in (7) is not considered just means that the oscillating term of order $1 / \Omega$ in the derivative of the speed is neglected, i.e. a speed perturbation term of order $1 / \Omega^{2}$ in (9) is neglected. Simulation results show that such first order approximation of the rotor speed response gives satisfactory results. In (8) we have also implicitly assumed that the load torque is a static function of the rotor speed. In this case effect of the load torque perturbation caused by the speed perturbation can be neglected (according to the averaging technique [19]). A simplified physical explanation is that the speed perturbation excited by the motor torque perturbation will be proportional to the speed perturbations (i.e. $1 / \Omega$ (see (9)). Consequently in the integration of the mechanical equation, effect of the load 
torque perturbation (if taken into account) can be neglected (in comparison to the effect of the electromagnetic torque perturbation) as it would result in the load torque related speed perturbation proportional to $1 / \Omega^{2}$. For resonant loads, where the load torque is a dynamic function of the speed, the above assumption is valid only if the harmonic frequency is not in vicinity of the resonance frequencies.

The rotor flux perturbations caused by the harmonic current injection and speed perturbations can be derived from (2):

$$
\dot{\varphi}_{r}=-\left(\tau_{r}{ }^{-1}+j \omega_{s}-j(\bar{\omega}+\delta \omega)\right) \varphi_{r}+R_{r e q}\left(\bar{i}_{s}+\delta i_{s}\right)
$$

In (10) the first order term of the speed perturbation $\delta \omega$ is included. After introduction of (6) and (9) into (10) the rotor flux perturbation dynamics is:

$$
\begin{aligned}
& \delta \dot{\varphi}_{r}=\left(R_{r e q} I^{+}+j \frac{3 n_{p}{ }^{2}}{4 J \Omega}\left(\bar{\varphi}_{r}{ }^{2} I^{-}-\left|\bar{\varphi}_{r}\right|^{2} I^{+}\right)\right) e^{j \Omega t}+ \\
& +\left(R_{r e q} I^{-}-j \frac{3 n_{p}{ }^{2}}{4 J \Omega}\left(\bar{\varphi}_{r}{ }^{2} I^{+}-\left|\bar{\varphi}_{r}\right|^{2} I^{-}\right)\right) e^{-j \Omega t}
\end{aligned}
$$

Integration of (11) gives:

$$
\begin{aligned}
& \delta \varphi_{r}=\left(-j \frac{R_{r e q} I^{+}}{\Omega}+\frac{3 n_{p}{ }^{2}}{4 J \Omega^{2}}\left(\bar{\varphi}_{r}^{2} I^{-}-\left|\bar{\varphi}_{r}\right|^{2} I^{+}+\right)\right) e^{j \Omega t}+ \\
& +\left(j \frac{R_{r e q} I^{-}}{\Omega}+\frac{3 n_{p}^{2}}{4 J \Omega^{2}}\left(\bar{\varphi}_{r}{ }^{2} I^{+}-\left|\bar{\varphi}_{r}\right|^{2} I^{-}\right)\right) e^{-j \Omega t}
\end{aligned}
$$

One can see that in (12) a partial expansion up to the second order of the flux response approximation is obtained (consequence of taking into account the speed perturbation term $\delta \omega$ in (10)). Inclusion of this second order term in the flux response approximation was necessary in get good matching between the analytical and simulation and experimental results.

Now from (1) the stator voltage response can be derived. It will be composed of several spectral components (seen in the synchronous fundamental frequency reference frame):

$$
\begin{aligned}
& v_{s}=L f \frac{d\left(\bar{i}_{s}+\delta_{i_{S}}\right)}{d t}-\left(\tau_{r}^{-1}-j(\bar{\omega}+\delta \omega)\right)\left(\bar{\varphi}_{r}+\delta \varphi_{r}\right)+ \\
& +\left(R_{e q}+j \omega_{s} L_{f}\right)\left(\bar{i}_{S}+\delta_{i_{S}}\right)= \\
& =V^{0}+V^{+} e^{j \Omega t}+V^{-} e^{-j \Omega t}+U^{+} e^{j 2 \Omega t}+U^{-} e^{-j 2 \Omega t}
\end{aligned}
$$

where $V^{0}$ is the fundamental frequency vector, $V^{+,-}$are the positive and negative sequence vectors rotating in opposite directions at the injection frequency, and $U^{+,-}$are the positive and negative sequence vectors rotating at twice the injection frequency. After introduction of the perturbation components $\delta_{i_{s}}, \delta \omega$ and $\delta \varphi_{r}$ in (6), (9) and (12) respectively into (13) and grouping the terms containing $e^{j \Omega t}$, the stator harmonic voltage vector component rotating at $+\Omega$ is:

$$
\begin{aligned}
& V^{+}=\left(R_{e q}+j\left(\omega_{s}+\Omega\right) L_{f}\right) I^{+}- \\
& -\left(\tau_{r}^{-1}-j \bar{\omega}\right)\left(-j \frac{R_{r e q} I^{+}}{\Omega}+\frac{3 n_{p}{ }^{2}}{4 J \Omega^{2}}\left(\bar{\varphi}_{r}{ }^{2} I^{-}-\left|\bar{\varphi}_{r}\right|^{2} I^{+}\right)\right)+ \\
& +j \frac{3 n_{p}{ }^{2}}{4 J \Omega}\left(\bar{\varphi}_{r}{ }^{2} I^{-}-\left|\bar{\varphi}_{r}\right|^{2} I^{+}\right)
\end{aligned}
$$

In a similar manner the stator harmonic voltage vector component rotating at $-\Omega$ can be found:

$$
\begin{aligned}
& V^{-}=\left(R_{e q}+j\left(\omega_{s}-\Omega\right) L_{f}\right) I^{-}- \\
& -\left(\tau_{r}{ }^{-1}-j \bar{\omega}\right)\left(j \frac{R_{r e q} I^{-}}{\Omega}+\frac{3 n_{p}{ }^{2}}{4 J \Omega^{2}}\left(\bar{\varphi}_{r}{ }^{2} I^{+}-\left|\bar{\varphi}_{r}\right|^{2} I^{-}\right)\right)- \\
& -j \frac{3 n_{p}{ }^{2}}{4 J \Omega}\left(\bar{\varphi}_{r}{ }^{2} I^{+}-\left|\bar{\varphi}_{r}\right|^{2} I^{-}\right)
\end{aligned}
$$

The above computations correspond to the first terms of asymptotic expansion of the solution (1-5) with respect to $1 / \Omega$. In our case the expansion is stopped at order $2\left(1 / \Omega^{2}\right)$. In further analysis of our particular interest is to find relationships between the rotor flux position error and voltage signals given in (14) and (15) for two typical harmonic current injection modes: rotational and pulsating.

\section{A. Rotational Harmonic Current Injection}

In this special case just one (let say) positive sequence rotational current harmonic vector is injected:

$$
I^{+}=I \quad I^{-}=0 \quad \delta i_{s}=I e^{j \Omega t}
$$

After introducing (16) into (15) we obtain:

$$
V^{-}=V_{d}{ }^{-}+j V_{q}{ }^{-}=-\frac{3 n_{p}{ }^{2} I}{4 J \Omega} \bar{\varphi}_{r}{ }^{2}\left(j+\frac{\tau_{r}{ }^{-1}-j \bar{\omega}}{\Omega}\right)
$$

Real part of the negative sequence harmonic voltage $V$ conveys information on the rotor flux position error:

$$
V_{d}^{-}=\operatorname{Re}\left(V^{-}\right)=\frac{3 n_{p}{ }^{2} I}{4 J \Omega}\left|\bar{\varphi}_{r}\right|^{2}\left(\left(1-\frac{\bar{\omega}}{\Omega}\right) \sin (2 \varepsilon)-\frac{\tau_{r}{ }^{-1}}{\Omega} \cos (2 \varepsilon)\right)
$$

Assuming that the rotor flux is not ideally aligned with the fundamental frequency controller reference frame $\bar{\varphi}_{r}=\left|\bar{\varphi}_{r}\right| e^{j \varepsilon}$ and that the flux position error $(\varepsilon)$ is small $(\varepsilon \approx 0$, $\sin (2 \varepsilon) \approx 2 \varepsilon$ and $\cos (2 \varepsilon) \approx 1)$, the scaling $K$, gain $A$ and offset $B$ terms can be identified in the position error signal (caused by the second order term in the flux response in (12)):

$$
\begin{aligned}
& V_{d}{ }^{-} \approx K(A \varepsilon+B) \\
& K=\frac{3 n_{p}{ }^{2} I}{2 J \Omega}\left|\bar{\varphi}_{r}\right|^{2} \quad A=\left(1-\frac{\bar{\omega}}{\Omega}\right) \quad B=-\frac{\tau_{r}{ }^{-1}}{2 \Omega}
\end{aligned}
$$

Magnitude of the scaling term $K$ is directly dependant on the injection current magnitude and inversely dependant on the load inertia and injection frequency. To obtain satisfactory signal/noise ratio, higher injection current and/or lower injection frequencies are needed especially when the load inertia is high. On other side the injection current magnitude is limited by the machine losses while low injection frequencies 
reduce achievable rotor position tracking bandwidth. So, for a given load inertia, a trade off must be made when selecting an appropriate level of the injection current and its frequency. Typical injection frequency is $25 \mathrm{~Hz}-50 \mathrm{~Hz}$ and injection current magnitude between $1 / 4-1 / 2$ of the motor nominal magnetizing current. From (18) we also can see that the gain term $A$ depends on the average rotor speed. To reduce this effect it is necessary to use the injection frequency considerably higher than the rotor speed range in which the rotor flux tracking is to be employed $(\Omega \gg \bar{\omega})$. The (undesirable) offset term $B$ in (18) has relatively low influence if $\Omega$ is kept sufficiently higher than $\tau_{r}^{-1}$. Additionally its effect can be compensated in a great extent (depending on $\tau_{r}$. parametric error) in a feed-forward manner in the normalised position error signal (after effect of the scaling $K$ is removed, see Section VI). Major disadvantage of the rotational injection is that it results in perpetual speed oscillations even if the controller is aligned with the rotor flux axis $(\varepsilon=0)$ :

$$
\delta \omega=-\frac{3 n_{p}{ }^{2}}{2 J \Omega}\left|\bar{\varphi}_{r}\right| I \cos (\Omega t)
$$

\section{B. Pulsating Harmonic Current Injection}

In this important special case a pulsating current injection is used i.e. both sequences of the rotational harmonic current injection vector are applied:

$$
I^{+}=I^{-}=\frac{I}{2} \quad \delta i_{s}=I \frac{e^{j \Omega t}+e^{-j \Omega t}}{2}=I \cos (\Omega t)
$$

Now the rotor flux position error signal can be extracted by combining the harmonic integral controller outputs of the both sequences:

$$
\begin{aligned}
& V=V^{-}-V^{+}=-j \Omega L_{f} I-j\left(\tau_{r}^{-1}-j \bar{\omega}\right) \frac{R_{r e q} I}{\Omega}- \\
& -j \frac{3 n_{p}{ }^{2} I}{4 J \Omega}\left(\bar{\varphi}_{r}{ }^{2}-\left|\bar{\varphi}_{r}\right|^{2}\right)
\end{aligned}
$$

Real part of the combined harmonic voltage $V$ is related to the rotor flux position error as follows:

$$
V_{d}=\operatorname{Re}(V)=\frac{3 n_{p}^{2} I}{4 J \Omega}\left|\bar{\varphi}_{r}\right|^{2} \sin (2 \varepsilon)-\frac{\bar{\omega}}{\Omega} R_{r e q} I
$$

The voltage expression given by (22) is similar to that given by (18). However it can be seen that here the rotor average speed affects the offset term. Effect of the offset term can be neglected if $\bar{\omega}$ is small compared to $\Omega$ or and/or approximately compensated (depending on $R_{\text {req }}$ parametric error) directly in the $V_{d}$ signal (22) in a feed-forward manner.

\section{Initial Rotor Magnet FluX Position Detection IN PERMANENT MAGNet SynCHRONOUS MACHINES}

In this section we will investigate how initial position of the rotor can be detected in PMSM by using the current controller shown in Fig. 1. For that, relations between the flux position error and harmonic current controller outputs have to be derived.
Model of a salient pole PMSM will be used for these derivations. In general case without using position sensor the controller reference frame may not be aligned with the flux/rotor frame. Thus the model will be written in the controller reference frame rotating at the stator frequency $\omega_{s}$ when there is an alignment error $\varepsilon$ between the flux and controller frames (Fig. 3).

$$
\begin{aligned}
& v_{s}=R_{S} i_{S}+L \frac{d i_{s}}{d t}+\Delta L \frac{d i_{s}{ }^{*}}{d t} e^{j 2 \varepsilon}+j \omega_{s}\left(L i_{s}-\Delta L i_{s}{ }^{*} e^{j 2 \varepsilon}\right)+ \\
& +j \omega\left(2 \Delta L_{i_{s}}^{*} e^{j 2 \varepsilon}+\bar{\varphi}_{m} e^{j \varepsilon}\right) \\
& \varphi_{s}=L_{i_{S}}+\Delta L_{i_{S}}{ }^{*} e^{j 2 \varepsilon}+\bar{\varphi}_{m} e^{j \varepsilon} \\
& L=\frac{L_{d}+L_{q}}{2} \\
& \Delta L=\frac{L_{d}-L_{q}}{2} \\
& \tau_{e}=\frac{3}{2} n_{p} \operatorname{Im}\left(\varphi_{s}^{*} i_{s}\right) \\
& \frac{d \omega}{d t}=\frac{n_{p}}{J}\left(\tau_{e}-\tau_{l}\right)
\end{aligned}
$$

The term $\bar{\varphi}_{m}$ presents the rotor magnet flux. The inductance terms $L$ and $\Delta L$ are the average and the saliency inductances respectively which values depend on the machine synchronous inductances $L_{d}$ and $L_{q}$.

As in the IM case it is initially assumed that the stator current vector is perturbed by an arbitrary elliptic harmonic signal injection. The average stator current $\bar{i}_{s}$ is assumed to be zero (during initial rotor position):

$$
i_{s}=\delta i_{s} \quad \delta i_{s}=I^{+} e^{j \Omega t}+I^{-} e^{-j \Omega t}
$$

The injected perturbation current creates following average and oscillating speed dynamics (from (27) and (28), after (29) is introduced in (24)):

$$
\begin{aligned}
\dot{\bar{\omega}} & =\frac{3 n_{p}{ }^{2}}{2 J} \operatorname{Im}\left(2 \Delta L I^{+} I^{-} e^{-j 2 \varepsilon}\right) \\
\delta \dot{\omega} & =\frac{3 n_{p}{ }^{2}}{2 J} \operatorname{Im}\left(\begin{array}{l}
\bar{\varphi}_{m} I^{+} e^{-j \varepsilon} e^{j \Omega t}+\Delta L I^{+^{2}} e^{-j 2 \varepsilon} e^{j 2 \Omega t}+ \\
+\bar{\varphi}_{m} I^{-} e^{-j \varepsilon} e^{-j \Omega t}+\Delta L I^{-2} e^{-j 2 \varepsilon} e^{-j 2 \Omega t}
\end{array}\right)
\end{aligned}
$$

After integration of (31), the speed oscillations are:

$$
\delta \omega=-\frac{3 n_{p}^{2}}{2 J} \operatorname{Re}\left(\begin{array}{l}
\frac{\bar{\varphi}_{m} I^{+} e^{-j \varepsilon}}{\Omega} e^{j \Omega t}+\frac{\Delta L I^{+^{2}} e^{-j 2 \varepsilon}}{2 \Omega} e^{j 2 \Omega t}- \\
-\frac{\bar{\varphi}_{m} I^{-} e^{-j \varepsilon}}{\Omega} e^{-j \Omega t}-\frac{\Delta L I^{-^{2}} e^{-j 2 \varepsilon}}{2 \Omega} e^{-j 2 \Omega t}
\end{array}\right)
$$

The stator voltage response can be derived if (29) and (32) are introduced in (23). Again the harmonic current injection results in multiple spectral components (at different frequencies and sequences) in the stator voltage response: 


$$
\begin{aligned}
& v_{S}=R_{S} i_{S}+L \frac{d \delta_{i_{S}}}{d t}+\Delta L \frac{d \delta_{i_{S}}{ }^{*}}{d t} e^{j 2 \varepsilon}+ \\
& +j \omega_{S}\left(L \delta i_{S}-\Delta L \delta_{i_{S}}{ }^{*} e^{j 2 \varepsilon}\right)_{+} \\
& +j(\omega+\delta \omega)\left(2 \Delta L \delta i_{S}{ }^{*} e^{j 2 \varepsilon}+\bar{\varphi}_{m} e^{j \varepsilon}\right)= \\
& =V^{0}+V^{+} e^{j \Omega t}+V^{-} e^{-j \Omega t}+U^{+} e^{+j 2 \Omega t}+U^{-} e^{-j 2 \Omega t}
\end{aligned}
$$

Of particular interest for the rotor flux position detection are two stator voltage vector components $V^{+}$and $V^{-}$rotating at the injection frequency $\pm \Omega$. Combining (23), (29) and (32) and extracting terms containing $e^{ \pm j \Omega t}$ yields:

$$
\begin{aligned}
& V^{+}=R_{S} I^{+}+j \Omega L I^{+}+j \Omega \Delta L I^{-} e^{j 2 \varepsilon}+j 2 \bar{\omega} \Delta L I^{-} e^{j 2 \varepsilon}- \\
& -j \frac{3 n_{p}{ }^{2}}{4 J \Omega}\left(\Delta L^{2}\left(I^{+^{2}}-I^{-2} e^{j 4 \varepsilon}\right) I^{+}+\bar{\varphi}_{m}{ }^{2}\left(I^{+}-I^{-} e^{j 2 \varepsilon}\right)\right) \\
& V^{-}=R_{S} I^{-}-j \Omega L I^{-}-j \Omega \Delta L I^{+} e^{j 2 \varepsilon}+j 2 \bar{\omega} \Delta L I^{+} e^{j 2 \varepsilon}- \\
& -j \frac{3 n_{p}{ }^{2}}{4 J \Omega}\left(\Delta L^{2}\left(I^{+^{2}} e^{j 4 \varepsilon}-I^{-2}\right) I^{-}+\bar{\varphi}_{m}{ }^{2}\left(I^{+} e^{j 2 \varepsilon}-I^{-}\right)\right)
\end{aligned}
$$

From (34) and (35) we can conclude that these voltage components are functions of the rotor flux angular position error $\varepsilon$. Thus they can be used for tracking of the rotor position. Further, similarly as in the IM case, one can consider two typical types of the harmonic injections: rotational and alternating current vector injections.

\section{A. Rotational Harmonic Current Injection}

When the rotational harmonic current vector is applied, the perturbation current vector is:

$$
\delta_{i_{s}}=I e^{j \Omega t} \text {, i.e. } I^{+}=I, I^{-}=0
$$

The negative sequence harmonic current vector is regulated to zero while the negative sequence harmonic voltage vector (37) is produced by the speed perturbations.

$$
V^{-}=-j\left(\Delta L(\Omega-2 \bar{\omega})+\frac{3 n_{p}^{2}}{4 J \Omega} \bar{\varphi}_{m}^{2}\right) I e^{j 2 \varepsilon}
$$

Real part ( $d$ axis component) of the negative sequence harmonic voltage vector conveys the rotor flux position error information:

$$
\begin{aligned}
& V_{d}{ }^{-}=\operatorname{Re}\left(V^{-}\right)=\left(\Delta L(\Omega-2 \bar{\omega})+\frac{3 n_{p}{ }^{2}}{4 J \Omega} \bar{\varphi}_{m}{ }^{2}\right) I \sin (2 \varepsilon) \approx \\
& \approx\left(2 I \Delta L(\Omega-2 \bar{\omega})+\frac{3 n_{p}{ }^{2} I}{2 J \Omega} \bar{\varphi}_{m}{ }^{2}\right) \varepsilon
\end{aligned}
$$

With this type of injection there will be no average component in the motor torque caused by the harmonic excitation $\left(\bar{\tau}_{e}=0\right)$ even in presence of the inductance saliency. However perpetual speed/torque oscillations will present even if the control system is perfectly aligned with the rotor reference frame (39):

$$
\delta \omega=-\frac{3 n_{p}{ }^{2}}{2 J \Omega}\left(\frac{\Delta L I^{2}}{2} \cos (2 \Omega t)+\bar{\varphi}_{m} I \cos (\Omega t)\right)
$$

\section{B. Pulsating Harmonic Current Injection}

In this case two harmonic current vectors are applied, with same magnitudes rotating at the harmonic frequencies $\pm \Omega$. It is equivalent to applying a pulsating harmonic current in the controller d axis:

$$
I^{-}=I^{+}=\frac{I}{2} \quad \delta i_{s}=I \frac{e^{j \Omega t}+e^{-j \Omega t}}{2}=I \cos (\Omega t)
$$

Again both sequences of the stator voltage at the injection frequency $(V)$ are combined to retrieve the rotor position. The $\mathrm{d}$ axis component of the combined voltage $V$ is dependant on the rotor flux position error:

$$
\begin{aligned}
& V=V^{-}-V^{+}=V_{d}+j V_{q} \\
& V_{d}=\operatorname{Re}(V)=\left(\Omega \Delta L+\frac{3 n_{p}{ }^{2}}{4 J \Omega}|\bar{\varphi}|_{m}{ }^{2}\right) I \sin (2 \varepsilon)+ \\
& +\frac{3 n_{p}{ }^{2}}{16 J \Omega} \Delta L^{2} I^{3} \sin (4 \varepsilon) \approx\left(2 \Omega \Delta L I+\frac{3 n_{p}{ }^{2} I}{4 J \Omega}|\bar{\varphi}|_{m}^{2}\right) \varepsilon
\end{aligned}
$$

With this type of excitation an average torque component can be produced if there is inductance saliency (30):

$$
\bar{\tau}_{e}=\frac{3}{4} n_{p} \Delta L I^{2} \sin (2 \varepsilon)
$$

Thus some rotor movements can be created if the load friction torque is negligible. An important advantage of the alternating signal injection is that there is no speed and torque oscillations when the rotor flux and controller reference frames are aligned (perturbation current applied in the flux direction). Therefore for practical applications this type of harmonic injection could be more acceptable.

\section{Magnet Flux Polarity Detection}

From the analysis presented one can see that the magnet flux position error signal is a function of double rotor flux position angular error $(2 \varepsilon)$. This fact means that in PMSM machines it is possible to detect (by using position tracking based on $2 \varepsilon$ signal) only position of the rotor magnet flux axis but not its orientation (or flux polarity, so called $0-\pi$ ambiguity). Thus an additional step is required to determine the rotor flux polarity).

If the PMSM machine has a saliency $(\Delta L \neq 0)$, it is possible to detect the flux polarity by using an extension of the proposed current controller. By using two sets of additional harmonic I controllers, placed in SRF frames rotating at $\pm 2 \Omega$, it is possible to extract the second harmonic voltage components $\left(U^{+}\right.$and $\left.U\right)$ which can be derived from (33):

$$
\begin{aligned}
U^{+} & =-j \frac{3 n_{p}^{2}}{2 J \Omega} \bar{\varphi}_{m} \frac{\Delta L I^{2}}{4} e^{-j \varepsilon} \\
U^{-} & =-j \frac{3 n_{p}^{2}}{2 J \Omega} \frac{5}{4} \Delta L I^{2} \bar{\varphi}_{m} e^{j 3 \varepsilon}
\end{aligned}
$$


Of particular interest is the $U^{+}\left(2^{\text {nd }}\right.$ harmonic positive sequence) component that is function of the position error $\varepsilon$ only. Thus the flux orientation can be unambiguously resolved by analyzing sign of the signal $\operatorname{Re}\left(U^{+}\right)$.

$$
U^{+}{ }_{d}=\operatorname{Re}\left(U^{+}\right)=-\frac{3 n_{p}{ }^{2}}{2 J \Omega} \bar{\varphi}_{m} \frac{\Delta L I^{2}}{4} \sin \varepsilon
$$

If the PMSM machine saliency is zero $(\Delta L=0)$, magnetic saturation effects must be used for the magnet flux polarity detection to resolve the $0-\pi$ ambiguity. The saturation creates an asymmetry between the positive and negative half periods of the injected voltage ( $2^{\text {nd }}$ harmonic). So it turns out that the phase information of the second harmonic can be again used for resolution of the $0-\pi$ ambiguity. The saturation effect can be amplified by boosting the harmonic injection magnitude at the end of the rotor position tracking phase so that the rotor flux polarity can be reliably resolved.

\section{Effects of Geometric and Saturation Induced Saliency}

It is important to emphasise that the rotor flux position error signal given by (38) and (42) exists in all PMSM machines, even if the inductance saliency term is zero $(\Delta L=0)$. Actually the inductance saliency term here presents a disturbance factor which affects magnitude of the error signal (function of the harmonic injection frequency and rotor speed, terms $\Delta L(\Omega-2 \bar{\omega})$ in (38) and $\Omega \Delta L$ in (42)). This is in a sharp contrast with various high frequency injection methods that need the inductance saliency for the rotor position detection. It is obvious that, if the injection frequency $\Omega$ is sufficiently increased, the term excited by the rotor oscillations $\frac{3 n_{p}{ }^{2} I}{4 J \Omega}|\bar{\varphi}|_{m}{ }^{2}$ will become negligible and the rotor flux position error will become available only via the inductance saliency term ( $\Omega \Delta L$ term relative effect is increased as the injection frequency is increased). In other words in the presence of the saliency, at particular intermediate injection signal frequencies, a strong interference between the two phenomena can appear. Then neither the low nor high frequency injection based sensorless detection methods are reliable. Thus the injection signal frequency should be sufficiently low or high that so that one of these two phenomena clearly dominates.

It is worth noting here that in the presence of magnetic saturation the saliency effect $(\Delta L \neq 0)$ can be present in otherwise cylindrical PMSM and IM machines. In this case an effective spatial anisotropy is created due to increased magnetic reluctance in the saturated flux paths. As the saturation level depends on the both axis currents, a crosscoupling saliency term will appear the inductance matrix (for more information on the standard model of saturated cylindrical AC machines see [21]). The saturation induced saliency inductance is a function of difference between the inductances seen by the injected signal when applied along the saturation axis (dynamic inductance) and perpendicularly to it (static inductance) and two times angle between the injection and saliency axis. It is clear that the saturation-induced saliency can affect the accuracy of the rotor flux position estimation based on the proposed method in a similar way as the geometric saliency. Particular problem in estimation of this influence is that position of the saturation saliency axis may depend on the load and/or flux level and may not be fixed to the rotor flux (rotor) position at all. However it can be seen from (38) and (42) that, when choosing the signal injection frequency, it is possible to choose it sufficiently low so that the parasitic term depending on the inductance saliency becomes relatively small compared to the term excited by the speed mechanical oscillations.

\section{ROTOR FLUX TRACKING}

In the analysis presented it has been shown that the rotor flux position error signal can be retrieved directly from the current harmonic controller outputs $V_{d}^{-}$or $V_{d}$ (depending on type of injection). After normalization we have:

$$
\varepsilon \approx \frac{1}{2} \frac{V_{d}}{V_{\text {Norm }}}
$$

where $V_{\text {Norm }}$ depends on type of the injection and can be deduced from equations (17), (22), (38) or (42). A rotor flux position tracking loop driven by using the error signal can be created by using, for example, a phase locked loop approach (PLL) as shown in Fig 4 (pulsating harmonic current vector injection is assumed). The control reference frame position can be aligned to the rotor by regulating the position error $\varepsilon$ to zero by using a PI controller:

$$
\omega_{s}(s)=\left(K_{p \varepsilon}+\frac{K_{i \varepsilon}}{s}\right) \varepsilon(s)
$$

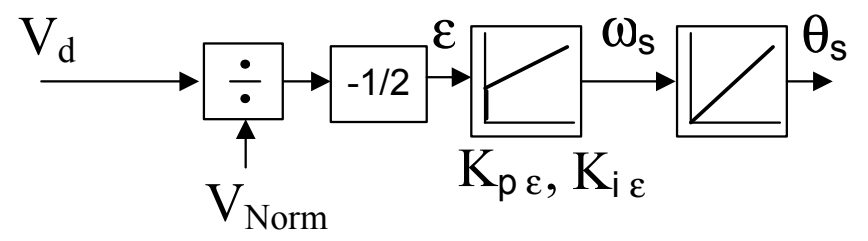

Fig. 4 .Rotor flux position tracking via a PLL.

Based on the flux position tracking loop, a sensorless field oriented vector control scheme applicable at low speeds can be constructed as shown in Fig. 5. The flux position tracking loop adapts the stator frequency and controller reference frame position so that the controller $d$ axis is kept in alignment with the rotor flux. The stator frequency signal (speed of the fundamental frequency control SRF) is used also for estimation of the rotor speed and closing the speed loop. Dynamic response of the rotor flux position error detection based on the low frequency injection is relatively slow compared to that of the fundamental frequency $[9,10]$ or high frequency injection based [13] sensorless control techniques. Thus the scheme of Fig. 5 could be practical mainly for loads that do not require high dynamics (not all loads require high dynamics). The low frequency harmonic injection based flux 
position error tracking can be also merged with a conventional fundamental frequency based flux estimator to improve the overall system dynamic response and robustness [9-10] or to expand speed range of the standard sensorless control [20].
One possibility is, for example, to employ it for adaptation of the stator resistance. But this topic is outside of scope of this paper.

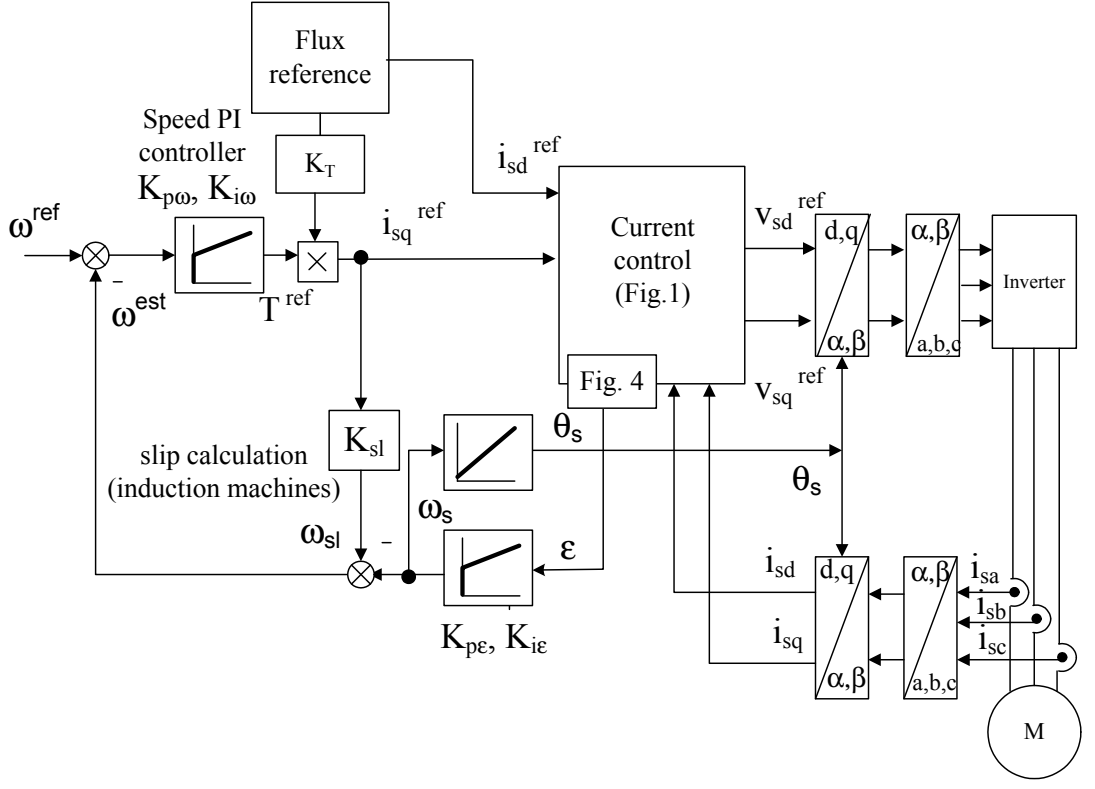

Fig. 5. Rotor flux oriented vector control with the rotor flux position tracking based on the low frequency harmonic current injection.

\section{EXPERIMENTAL RESULTS}

Several experimental tests have been performed to check validity of the theoretical analysis and illustrate opportunities for practical implementations of the flux position error detection method. The motor and controller parameters used in these experiments can be found in the Appendix 2.

\section{A. Rotor Flux Position Error Signal Validation with IM and Rotational Harmonic Injection}

In this experiment a $4 \mathrm{~kW}, 1445 \mathrm{rpm}, 7.9 \mathrm{~A}, 415 \mathrm{~V}, 50 \mathrm{~Hz} \mathrm{IM}$ was used (motor data found Appendix 2). The aim was to validate the expression for the position error (18) (rotational harmonic injection). For this the IM machine was supplied in the current control mode with nominal current and constant stator frequency $\omega_{s}$ by using a commercial $4 \mathrm{~kW} 400 \mathrm{~V}$ variable speed drive with modified control software. The inverter deadtime has been compensated by hardware while effect of the inverter switches voltage drop was approximately compensated in software by using the switch voltage drop model. The harmonic injection frequency was set at $25 \mathrm{~Hz}$ while the harmonic current magnitude was set at $50 \%$ of the nominal magnetising current $\left(I_{d n}=4.9 \mathrm{~A}\right)$. The current injection level is set on the upper limit of the typical range between $25 \%-50 \%$ of $I_{d n}$ (between $20 \%-35 \%$ of the nominal current, depending on machine) in order to maximize the position error signal to noise ratio. From the author's practical experience, if the high frequency injection method is used for tracking of saturation induced saliency $(5 \%-10 \%)$, the injection current level has to be in a comparable range, between $15 \%-25 \%$ of the nominal motor current. However the low frequency injection will produce lower losses than the high frequency injection. Thus it is believed that the injection current level chosen in the experimental tests is not impractical.

In no load conditions, the machine slip is zero and the rotor flux is aligned with the current injection (controller $\mathrm{d}$ axis, $\varepsilon=0$ ). When the load torque is applied to the rotor, the rotor slips and hence the rotor flux position drifts from the controller $d$ axis $(\varepsilon \neq 0)$. In this way it is possible to qualitatively experimentally verify the link between the $V_{d}$ voltage and rotor flux position error (18) simply by changing the load torque.

The results of Fig. 6 show that there is a nearly constant offset term in the $V_{d}^{-}$voltage independent of the load or stator frequency (slight variations are caused by the flux level changes). The measured offset is higher than that predicted by (18) if the standard machine parameters Table 1 are used in the calculations. This is attributed to a reduction of the magnetising inductance seen by the injected signal due to saturation (dynamic inductance). It can be also seen that the load torque toggling and corresponding flux position errors are detectable from the $V_{d}^{-}$signal. At low stator frequency $(2 \mathrm{~Hz}$, Fig. 6 (a) and (b)) the gain term is similar for both rotor speed directions. At higher stator frequencies $(10 \mathrm{~Hz}$, Fig. 6 (c) and (d)), the gain term in $V_{d}^{-}$is significantly affected by the sign of the stator frequency. This is in good qualitative agreement with the theory (effect of the gain term $1-\bar{\omega} / \Omega$ in (18)). 


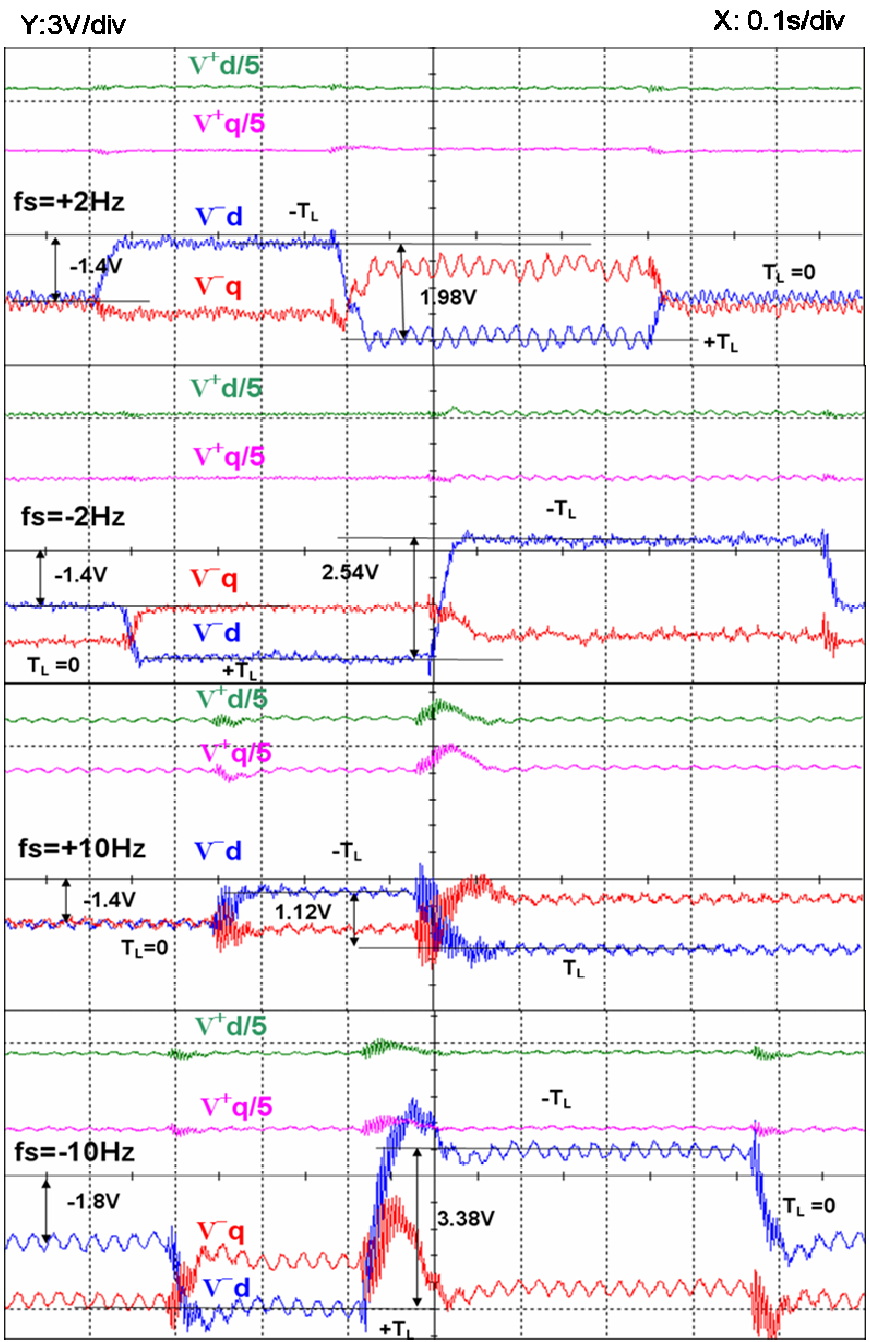

Fig. 6. Outputs of the harmonic I controllers with rotational signal injection at various stator frequencies and load torques.

\section{B. Rotor Flux Position Error Validation with IM and Pulsating Harmonic Injection}

Several measurements with the pulsating signal injection have been made. The only difference compared to the previous experiment is that the harmonic injection is applied only in the controller $d$ axis. The flux position error caused by the load torque changes is reflected in the $V_{d}$ signal as illustrated in Fig. 7. One can see that the $V_{d}$ signal (in Fig. 7 is shown $V_{d}^{+}-V_{d}^{-}=-V_{d}$ ) contains an offset which magnitude and sign are speed dependant. The gain term is not dependant on the speed. Regardless of the speed, the load torque toggling always creates same swings in the $V_{d}$ signal. These results are in full agreement with the theoretical result given by (22). The ripple visible in the $V_{d}^{+}-V_{d}^{-}$signal in Fig. 7 is due to the presence of higher order harmonics that are not specifically rejected by additional I controllers rotating in respective SRF frames. Although effect of this ripple on the control performance is considerably attenuated by the machine transfer function, it is a major limiting factor for practically achievable speed loop and torque rejection control bandwidths.

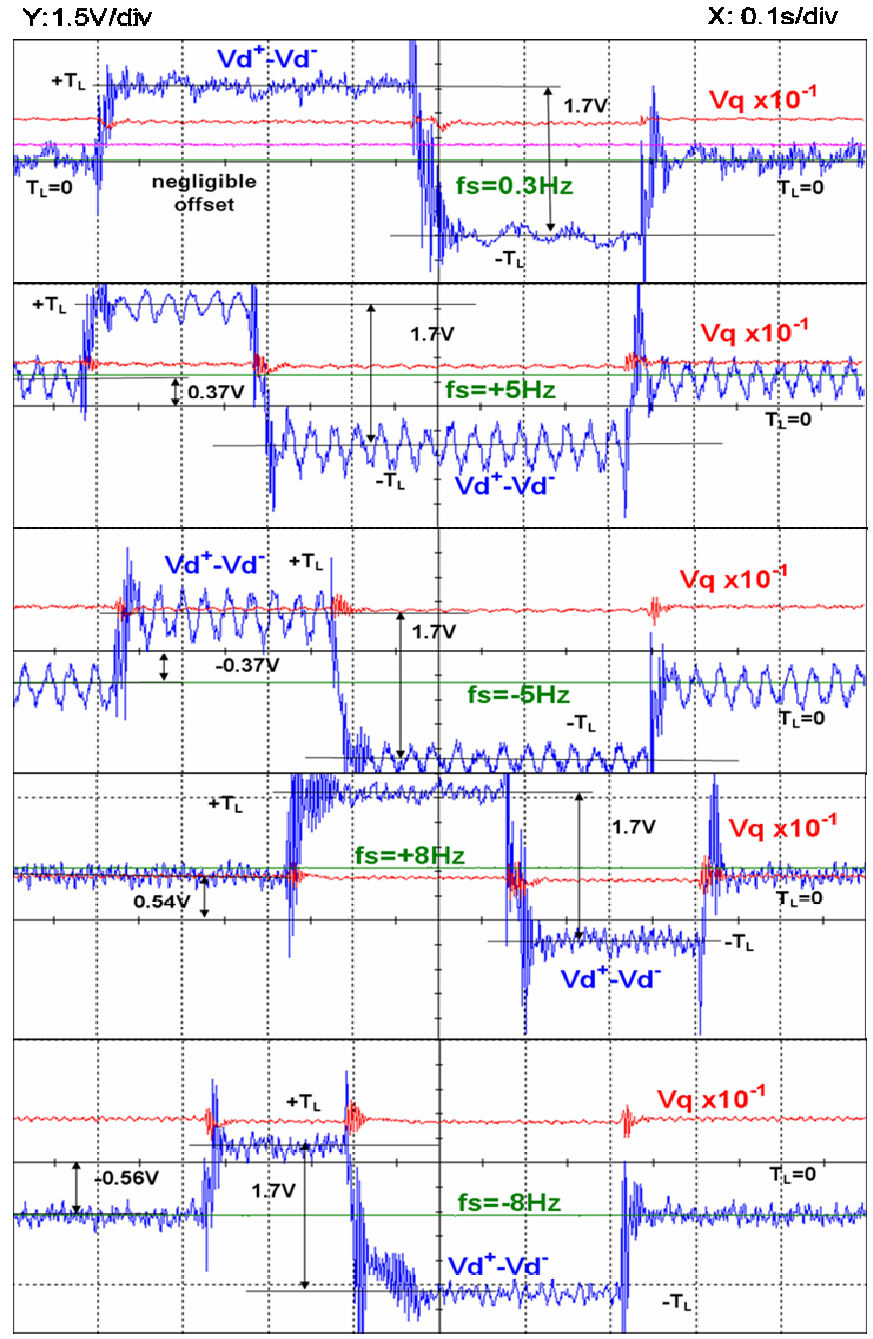

Fig. 7. Outputs of the combined harmonic I controller outputs with pulsating signal injection at various stator frequencies and load torques.

\section{Sensorless Vector Control of IM}

The controller of Fig. 5 was used to demonstrate vector control of the IM at near zero speed. The external speed loop was activated and speed reference was set at $1.5 \mathrm{~Hz}$. The pulsating harmonic injection of $50 \%$ of the motor nominal magnetising current $\left(I_{d n}=4.9\right.$ Apeak $)$ at $25 \mathrm{~Hz}$ was applied in this case. This control method is aimed for the low speed range between $0 \%-10 \%$. The method could be applied at higher speeds but the major limiting point is management of saturations in the control of the stator currents and voltage.

Figure 8 shows the situation when the load torque was increased in negative direction forcing the motor to operate in the regeneration. In the experiment the torque control could be maintained even when the stator frequency reached zero. However, similarly as in [8-9], it is found that only relatively low to moderate control dynamics is achievable (largely dependent on the injection frequency $\Omega$ ) by using the low frequency injection technique. The method can be easily used for applications that do not require a speed tracking (speed cycle tracking and torque disturbance rejection) with a bandwidth more than $1 \mathrm{~Hz}$. In our tests the speed control loop bandwidth was set to $1 \mathrm{~Hz}$ (Table 3 ). 


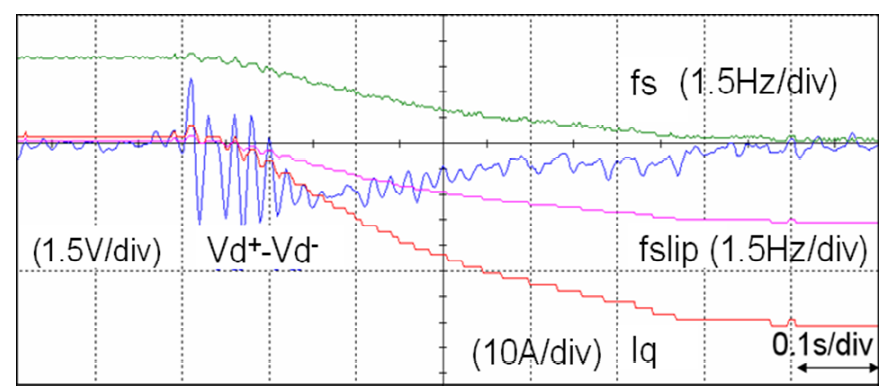

Fig 8. Correction of the rotor flux position error near zero frequency after load torque increase.

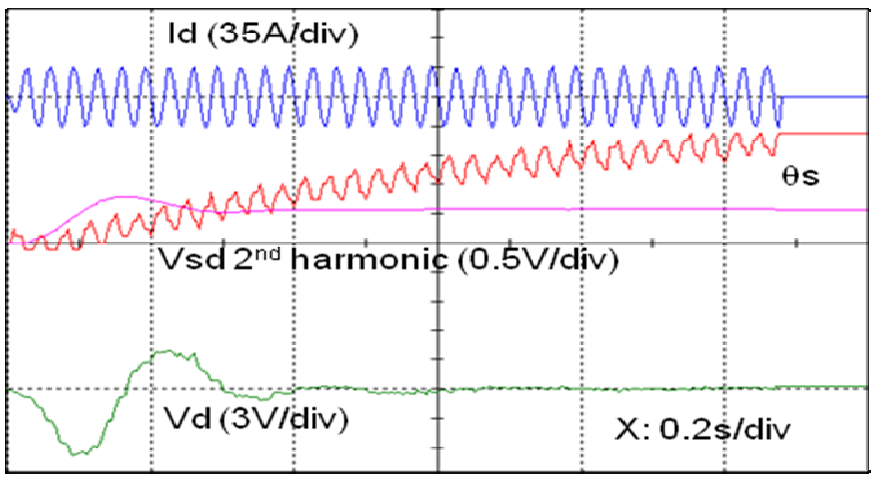

Fig 9. Convergence of the position tracking in PMSM. Flux polarity detection based on observation of sign of the second harmonic in the stator voltage reference (no correction by $\pi$ ).

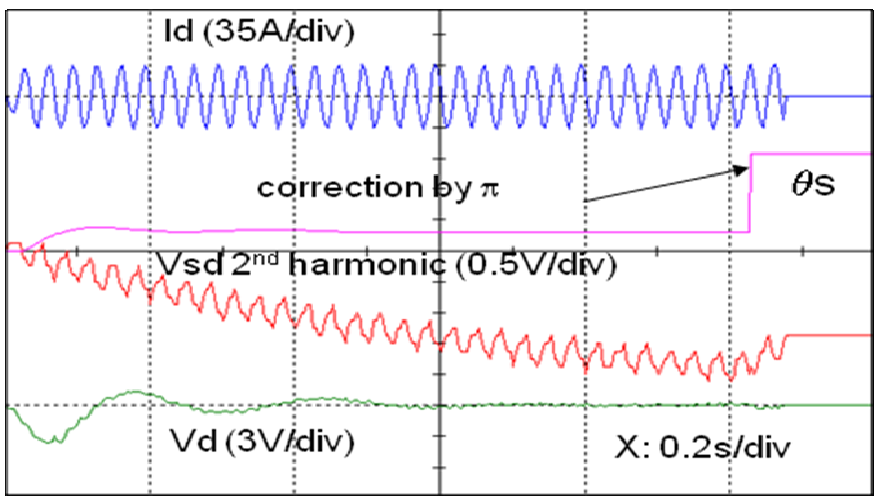

Fig 10. Convergence of the position tracking in PMSM. Flux polarity detection based on observation of sign of the second harmonic in the stator voltage reference (correction by $\pi$ ).

\section{Initial Rotor Position Detection in PMSM with Pulsating Harmonic Injection}

Finally the initial rotor position detection has been verified on a PMSMs with low saliency (Appendix 2, Table 2, $L_{d}=90 \% L_{q}$ ) using the scheme of Fig. 4 and detection of phase of the second harmonic for the flux polarity ambiguity resolution. In this test the pulsating $d$ axis harmonic current injection was applied with magnitude $I=25 \%$ of the motor nominal current at frequency $\Omega=2 \pi \times 30 \mathrm{~Hz}$. As qualitatively illustrated in Fig. 9 the rotor position tracking (based on regulating the normalised composite voltage $V_{d}$ to zero, see Section VI) converges within $500 \mathrm{~ms}$. The rotor flux polarity is resolved by observation of the sign of the second harmonic in the stator voltage response (i.e. half period asymmetryinjection in direction of the flux requires lower voltage that injection in the opposite direction. Figure 10 illustrates qualitatively a situation when the controller position angle is corrected by $\pi$ after the tracking phase has been completed. The ripple in Figs. 9 and 10 in the $2^{\text {nd }}$ harmonics voltage waveform is due to the presence of the $3^{\text {rd }}$ harmonic that is not specifically rejected by additional I controllers rotating in SRF frames at $3 \Omega /-3 \Omega$.

In the tests, the initial rotor position detection method enabled smooth starts of the PMSM without uncontrolled rotor movements. Although a full statistical characterization of the position error has not been completed, after performing several dozens of tests, an assessment of the estimated position accuracy has been made by comparing it with the position obtained by using the rotor position sensor (resolver). These tests indicate that the position error depends on the injection frequency and current magnitude. For example, with the injection current set to $20 \%$ and frequency at $50 \mathrm{~Hz}$, the initial position estimation error was within $\pm 15 \mathrm{deg}$. With the injection current set $50 \%$ of the nominal and frequency at $30 \mathrm{~Hz}$ the error was within $\pm 10 \mathrm{deg}$.

While various high frequency signal injection based methods can provide superior tracking dynamics, some important features of the method are that it does not require any rotor saliency, does not produce considerable audible noise and it is more suited for applications with a long shielded motor cable and/or inverter output (sinus) filter.

\section{CONCLUSIONS}

This paper proposes a method for extraction of the rotor flux position error by using a stator current control scheme typically found in selective active power filter control systems. This current controller integrates two tasks: stator current harmonic injection control and spectral decomposition of the stator voltage response. In the proposed method six or eight (with the $2^{\text {nd }}$ harmonic detection) SRF based integral current controllers are used, dedicated to every spectral component of interest. In this way the fundamental and harmonic current injections are performed with zero steadystate error while respective spectral components of the stator voltage response are readily available at the SRF integrator outputs without any additional signal processing. By using the perturbation techniques the links between the harmonic integral controller outputs and rotor flux position error have been established in either IM or PMSM machines and with two characteristic types of the harmonic injections (rotational and pulsating).

The proposed approach has been validated in several experiments. Initially by applying the low frequency harmonic current injection into an IM it is experimentally confirmed that extraction of the rotor flux position error from the harmonic I controller outputs is feasible according to the theoretical result presented. Further it was experimentally demonstrated that the flux position error can be used for the rotor flux oriented sensorless control at very low stator frequencies or for initial rotor position detection in PMSMs.

In future work several topics are to be further studied: dynamic response and stability analysis of the sensorless control, optimal current controller gain selection, effects the 
inverter non-linearities (dead-time, switching devices voltage drop) and effects of the current acquisition and motor parameter errors.

\section{APPENDIXES}

\section{A. Appendix 1}

For the closed loop stability of the current PI controller with additional harmonic I controllers it is sufficient to consider the simple (for example IM) model:

$$
L_{f} \frac{d}{d t} i_{s}=v_{s}-R_{e q} i_{s}+w
$$

Where $w$ is a perturbation term assumed almost constant here. If we take:

$$
i_{S}{ }^{r e f}=\bar{i}_{s}+I^{+} e^{j \Omega t}+I^{-} e^{-j \Omega t}
$$

where $\Omega$ is harmonic injection frequency and $I^{+}$and $I^{-}$are constant magnitudes. The current controller yields the following stator voltage:

$$
\begin{aligned}
& v_{s}=-w+R_{e q} i_{s}{ }^{r e f}+L_{f} \frac{d}{d t} i_{s}^{r e f}+K_{p}\left(i_{s}{ }^{r e f}-i_{S}\right)+ \\
& +K_{i} \int_{0}^{t}\left(i_{S} r e f(\tau)-i_{S}(\tau)\right) d \tau+ \\
& +K_{i h}\left(\begin{array}{l}
e^{j \Omega t} \int_{0}^{t}\left(i_{s} r e f(\tau)-i_{S}(\tau)\right) e^{-j \Omega t} d \tau+ \\
e^{-j \Omega t} \int_{0}^{t}\left(i_{S} r e f(\tau)-i_{S}(\tau)\right) e^{j \Omega t} d \tau
\end{array}\right)
\end{aligned}
$$

The closed loop system has tree additional complex variables, three integral terms as state variables. They will be denoted by $\bar{x}, x^{+}$and $x^{-}$. The closed loop dynamics is then:

$$
\begin{aligned}
& L_{f} \frac{d}{d t} i_{S}=K_{p}\left(i_{s} r e f-i_{S}\right)+K_{i} \bar{x}+K_{i h} x^{+} e^{j \Omega t}+K_{i h} x^{-} e^{-j \Omega t}+ \\
& +R_{e q}\left(i_{s}{ }^{r e f}-i_{S}\right)+L_{f} \frac{d}{d t} i_{S} r e f \\
& \frac{d}{d t} \bar{x}=i_{S}{ }^{r e f}-i_{S} \\
& \frac{d}{d t} x^{+}=\left(i_{s}{ }^{r e f}-i_{S}\right) e^{-j \Omega t} \\
& \frac{d}{d t} x^{-}=\left(i_{s}{ }^{r e f}-i_{S}\right) e^{j \Omega t}
\end{aligned}
$$

The closed loop system is stable as far as the controller gain $K_{p}, K_{i}$ and $K_{i h}$ are strictly positive and $\Omega \neq 0$. This results from convergence to zero of the linear time invariant system:

$$
\begin{aligned}
& \frac{d}{d t} z_{1}=-\frac{K_{p}+R_{e q}}{L_{f}} z_{1}+\frac{K_{i}}{L_{f}} z_{2}+\frac{K_{i h}}{L_{f}}\left(z_{3}+z_{4}\right) \\
& \frac{d}{d t} z_{2}=-z_{1} \\
& \frac{d}{d t} z_{3}=-z_{1}+j \Omega_{z_{3}}
\end{aligned}
$$

$$
\frac{d}{d t} z_{4}=-z_{1}-j \Omega_{z_{4}}
$$

where $\quad\left(z_{1}, \quad z_{2}, \quad z_{3}, \quad z_{4}\right) \quad$ stands for $\left(i_{S}-i_{S}{ }^{r e f}, \bar{x}, x^{+} e^{j \Omega t}, x^{-} e^{-j \Omega t}\right)$. This formulation admits $\left|z_{1}\right|^{2}+K_{i} / L_{f}\left|z_{2}\right|^{2}+K_{i h} / L_{f}\left(\left|z_{3}\right|^{2}+\left|z_{4}\right|^{2}\right) \quad$ as Lyapunov function:

$$
\frac{d V}{d t}=-2 \frac{K_{p}+R_{e q}}{L_{f}}\left|z_{1}\right|^{2}
$$

Invariance Lasalle principle shows that $z$ converges to zero.

\section{B. Appendix 2}

In this Appendix we list all relevant motors and controller parameters used in the tests in Section VII.

Table 1. Parameters of IM.

\begin{tabular}{|c|l|}
\hline$P_{n}$ & $4 \mathrm{~kW}$ \\
\hline$V_{n}$ & $415 \mathrm{~V}$ \\
\hline$I_{n}$ & $7.9 \mathrm{~A}$ \\
\hline$f_{n}$ & $50 \mathrm{~Hz}$ \\
\hline$N_{n}$ & $1445 \mathrm{rpm}$ \\
\hline$J$ (estimated) & $0.02 \mathrm{kgm}^{2}$ \\
\hline$n_{p}$ & 2 \\
\hline$I_{d n}$ & $4.9 \mathrm{~A}$ \\
\hline$L_{f}$ & $10 \mathrm{mH}$ \\
\hline$L_{r}=L_{s}$ & $0.16 \mathrm{H}$ \\
\hline$R_{s}$ & $1.55 \Omega$ \\
\hline$R_{r e q}$ & $0.9 \Omega$ \\
\hline
\end{tabular}

Table 2. Parameters of PMSM.

\begin{tabular}{|c|l|}
\hline$I_{n}$ & $19.9 \mathrm{~A}$ \\
\hline$T_{n}$ & $25 \mathrm{Nm}$ \\
\hline$f_{n}$ & $200 \mathrm{~Hz}$ \\
\hline$J$ & 0.00514 \\
\hline$n_{p}$ & $3 \mathrm{kgm}^{2}$ \\
\hline$\varphi_{m}$ (peak) & $0.2 \mathrm{~Wb}$ \\
\hline$L_{d}$ & $4.25 \mathrm{mH}$ \\
\hline$L_{q}$ & 4.75 \\
\hline
\end{tabular}

Table 3. Controller parameters used in the tests.

\begin{tabular}{|l|l|c|l|}
\hline$K_{p}$ & $\omega_{0} L^{(*)}$ & $\omega_{\varepsilon}$ & $2 \pi f_{\varepsilon}$ \\
\hline$K_{i}$ & $\omega_{0}{ }^{2} L^{(*)}$ & $f_{\varepsilon}$ & $5 \mathrm{~Hz}$ \\
\hline$K_{i h}$ & $\Omega^{2} L^{(*)}$ & $K_{p \omega}$ & $2 J \xi_{\omega} \omega_{\omega}^{(*)}$ \\
\hline$\omega_{0}$ & $2 \pi f_{0}$ & $K_{i \omega}$ & $J \omega_{\omega}^{2(*)}$ \\
\hline$f_{0}$ & $50 \mathrm{~Hz}$ & $\omega_{\omega}$ & $2 \pi f_{\omega}$ \\
\hline$K_{p \varepsilon}$ & $2 \xi_{\varepsilon} \omega_{\varepsilon}$ & $f_{\omega}$ & $1.5 \mathrm{~Hz}$ \\
\hline$K_{i \varepsilon}$ & $\omega_{\varepsilon}^{2}$ & $\xi_{\varepsilon}=\xi_{\omega}$ & 1 \\
\hline
\end{tabular}

(*) The controller gains are dependent on machine parameters: inductance $L$ ( $L_{f}$ or $L_{d}$ and $L_{q}$ for IM and PMSM respectively) and rotor inertia $J$.

\section{REFERENCES}

[1] P. L. Jansen, R. D. Lorenz, "Transducerless Field Orientation Concepts Employing Saturation-Induced Saliencies in Induction Machines", IEEE Transactions on Industry Applications, Vol. 32, No. 6, Nov./Dec. 1996, pp. 1380-1393. 
[2] M. Linke, R. Kennel, J. Holtz, "Sensorless Position Control of Permanent Magnet Synchronous Machines without Limitation at Zero Speed", Proceedings of IEEE 28th Annual conference of Industrial Electronics Society, IECON 02, Vol. 1, Nov. 2002, pp. 674-679.

[3] J.-H. Jang, S.-K. Sul, J.-I. Ha, K. Ide, M. Sawamura, "Sensorless Drive of Surface-Mounted Permanent-Magnet Motor by High-Frequency Signal Injection Based on Magnetic Saliency", IEEE Transactions on Industry Applications', Vol. 39, No. 4, July/Aug. 2003, pp. 1031-1039.

[4] M. Linke, R. Kennel, J. Holtz, "Sensorless Speed and Position Control of Synchronous Machines using Alternating Carrier Injection", Proceedings of IEEE International Electrical Machines and Drive Conference, IEMDC'03, Vol. 2, June 2003, pp. 1211-1217.

[5] Joohn Sheok Kim, Seung Ki Sul, "New Stand-Still Position Detection Strategy for PMSM Drive without Rotational Transducers", Conference Proceedings of the Ninth Annual Applied Power Electronics Conference and Exposition, APEC '94., Vol. 1, 13-17 Feb. 1994 , pp.363 - 369 .

[6] E.K.K. Sng, A-C. Liew, T.A. Lipo, "New Observer-Based DFO Scheme for Speed Sensorless Field-Oriented Drives for Low-ZeroSpeed Operation", IEEE Transactions on Power Electronics, Vol. 13, No. 5, Sep. 1998, pp. 959-968.

[7] V.-M. Leppanen, J. Luomi, "Rotor Flux Angle Tracking Controller for Sensorless Induction Motor Drives", IEEE Industry Applications Conference, $37^{\text {th }}$ IAS Annual Meeting, Vol. 2, Oct. 2002, pp. 856-863.

[8] V.-M. Leppanen, J. Luomi, "Speed-Sensorless Induction Machine Control for Zero Speed and Frequency", IEEE Transactions on Industrial Electronics, Vol. 51, No. 5, Oct. 2004, pp. 1041-1047.

[9] M. Hinkkanen, V-M. Leppanen, J. Luomi, "Flux Observer Enhanced with Low-Frequency Signal Injection Allowing Sensorless ZeroFrequency Operation of Induction Motors", IEEE Transactions on Industry Applications, Vol. 41, No. 1, Jan./Feb. 2005, pp. 52-59.

[10] V.-M. Leppanen, J. Luomi, "Observer Using Low-Frequency Injection for Sensorless Induction Motor Control - Parameter Sensitivity Analysis", IEEE Transactions on Industrial Electronics, Vol. 53, No. 1, Feb. 2006, pp. 216-224.

[11] T. Kereszty, V-M Leppanen, J. Luomi, "Sensorless Control of Surface Magnet Synchronous Motors at Low Speeds Using Low-Frequency Signal Injection", The 29th Annual Conference of the IEEE Industrial Electronics Society IECON'03, Nov. 2003, pp. 1239-1243.

[12] M. Eskola, H. Tuusa, "Sensorless Control of Salient Pole PMSM Using a Low -Frequency Signal Injection", European Conference on Power Electronics and Applications, Sept. 2005, pp. 1-10.

[13] S. Wu, Y. Li, X. Miao, "Comparison of Signal Injection Methods for Sensorless control of PMSM at Very Low Speeds", IEEE Power Electronics Specialists Conference, PESC 2007, June 2007 pp. 568 573.

[14] S. Ogasawara, H. Akagi, "An Approach to Real-Time Position Estimation at Zero and Low Speed for a PM Motor Based on Saliency", IEEE Transactions on Industry Applications, Vol. 34, No. 1, Jan./Feb 1998, pp. 163-168.

[15] M. A. Vogelsberger, S. Grubic, T.G. Habetler, T.M. Wolbank, "Using PWM-Induced Transient Excitation and Advanced Signal Processing for Zero-Speed Sensorless Control of AC Machines", IEEE Transactions on Industrial Electronics, Vol. 57, No. 1, January 2010, pp. 365-374.

[16] S.J. Lee, S.K. Sul, "A Harmonic Reference Frame Based Current Controller for Active Filter", Fifteenth Annual IEEE Applied Power Electronics Conference and Exposition, 2000. APEC 2000, Vol. 2, 610 Feb. 2000, pp. $1073-1078$.

[17] D. Basic, V.S. Ramsden, P.K. Muttik, "Harmonic Filtering of HighPower 12-Pulse Rectifier Loads with a Selective Hybrid Filter System", IEEE Transactions on Industrial Electronics, Vol. 48, No. 6, Dec. 2001, pp. $1118-1127$.

[18] Xiao Peng, K.A. Corzine, G.K. Venayagamoorthy,"Multiple Reference Frame-Based Control of Three-Phase PWM Boost Rectifiers under Unbalanced and Distorted Input Conditions", IEEE Transactions on Power Electronics, Vol. 23, No. 4 July 2008, pp. 2006-2016.

[19] Hassan K. Khalil, "Nonlinear Systems", Prentice Hall, Third Edition, 2002, Chapter 10.4, Pages 402-411.

[20] C. Silva, G.M. Asher, M. Sumner, "Hybrid Rotor Position Observer for Wide Speed Range Sensorless PM Motor Drives Including Zero Speed', IEEE Transactions on Industrial Electronics, Vol. 53, No. 2, April 2006, pp. 373-378.
[21] P. Vas, "Vector Control of AC Machines", Oxford University Press, USA, 1990.

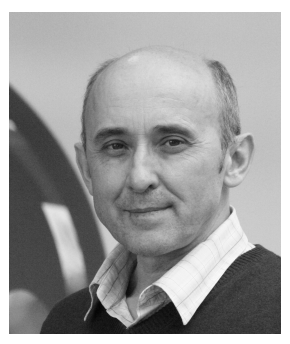

Duro Basic received the Dipl. Ing. degree in electrical engineering from the University of Novi $\mathrm{Sad}$, Serbia, the M.E. degree in electrical engineering from the University of Belgrade, Serbia, in 1993, and the Ph.D. degree in electrical engineering from the University of Technology, Sydney, Australia, in 2001. In 2002 he joined PDL Electronics, Schneider-Electric R\&D centre in Napier, New Zealand, as an Electrical Engineer/Senior Engineer working on design and development of standard variable speed drives. In 2006 he joined Schneider-Electric R\&D centre in Pacy-sur-Eure, France where he was working as a Senior Control Engineer/Schneider Group Expert on developments of motor control systems. Since November 2010 he has joined General Electric, Controls \& Power Electronics Centre of Excellence in Munich, Germany, as a Senior Power Conversion Engineer. His research interests are control and design of power electronics converters and electric drives, active filtering and power quality.

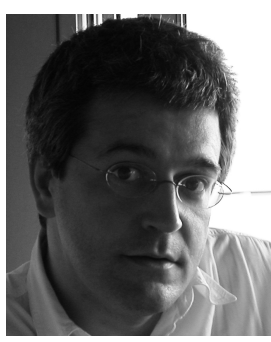

Francois Malrait (M'05) received the diploma of engineer from the Ecole Supérieure d'Electricité (Gif sur Yvette) in 1995 and the $\mathrm{PhD}$ degree in automatica and applied mathematics in 2001 from the Centre Automatique et Systèmes at Mines ParisTech. In 2000, he joined Motor Control team in Schneider Toshiba Inverter (STI). Since 2010, he is head of the Pacy Technology Center for Motion\&Drive department of Schneider Electric. $\mathrm{He}$ is in charge of anticipation and predevelopment for the standard drive offer. His fields of interest are identification and nonlinear control of power electronics, electrical machines, and applications of speed drives.

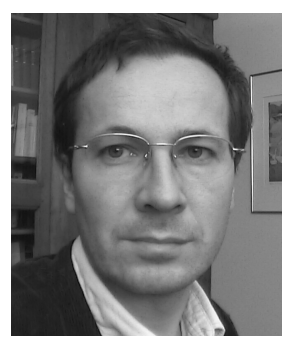

Pierre Rouchon was born in 1960 in SaintEtienne, France. Graduated from Ecole Polytechnique in 1983, he obtained his $\mathrm{PhD}$ in Chemical Engineering at Mines ParisTech in 1990. In 2000, he obtained his "habilitation à diriger des recherches" in Mathematics at University ParisSud Orsay. From 1993 to 2005, he was associated professor at Ecole Polytechnique in Applied Mathematics. From 1998 to 2002, he was the head of the Centre Automatique et Systèmes of Mines ParisTech. $\mathrm{He}$ is now professor at Mines ParisTech. His fields of interest include nonlinear control and system theory with its applications. His contributions include differential flatness and its extension to infinite dimensional systems, nonlinear observers and symmetries, process control, motion planning and tracking for mechanical systems, feedback stabilization and estimation for electrical drives, internal combustion engines and quantum systems. 